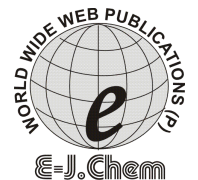

http://www.e-journals.net

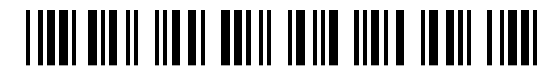

ISSN: 0973-4945; CODEN ECJHAO

E-Journal of Chemistry

Vol. 4, No. 2, pp 287-293, April 2007

\title{
Optimization of Gallic Acid Production from Terminalia Chebula by Aspergillus niger
}

\author{
N. LOKESWARI* and K. JAYA RAJU \\ Center for Bio-technology, \\ Department of Chemical Engineering, \\ Andhra University, Visakhapatnam- 530003. \\ E-Mail:lokeswarin@hotmail.com
}

Received 23 November 2006; Accepted 22 December 2006

\begin{abstract}
A method for producing gallic acid by microbiological hydrolysis of the tannins of myrobalan seed powder is described in the present work. Hydrolysis of gallotannins of the substrate to gallic acid by Aspergillus niger MTCC 282 was studied. A simple extraction procedure is used. Fungal mycelia pre-induced with $5 \mathrm{~g} / \mathrm{L}$ gallotannin was used as inoculums. Optimal conditions of production were determined using various parameters including gallotannin concentration, nutritional source and metal ions are determined. Gallotannin is hydrolyzed with acid, and gallic acid in the hydrolyses is then assayed using rhodanine. This method is very specific: no interferences from other plant phenolics, including ellagic acid and condensed tannin, have been observed. The yield of gallic acid with respect to gallotannins present in the substrate is estimated. Yields of gallic acid are about $74 \%$ with respect to gallotannin concentration, which suggests that this method is exploitable industrially for the manufacturing trimethoprim drug.
\end{abstract}

Keywords: Gallotannins, Gallic acid, Fungal Tannase, Fermentation

\section{Introduction}

The major contribution to gallotannin fermentation was that of Knudson $1913^{1}$, he demonstrated the toxic nature of tannic acid to most of the fungi at low concentration except various species of Aspergillus and Penicillium. These organisms tolerated around $10 \%$ tannic acid in the medium and detoxify it through enzymatic breakdown of tannic acid to gallic acid and further to carbon dioxide and water. This property of hydrolysis of gallotannins by $A$. niger has been exploited to manufacture gallic acid from Tara and Sumac tannins ${ }^{2}$. 
Tannase, an inducible extra - cellular enzyme produced by a number of animals, plants and microbes, has wide application in tannery, alcohol industry, pharmaceuticals and beverage industries. It is also responsible for the bioconversion of hydrolysable tannins to gallic acid ${ }^{3-4}$.

The present work deals with the development of process for microbial hydrolysis of gallotannins from terminalia chebula to gallic acid, by Aspergillus niger MTCC 282.

Myrobalan is a potential raw material for the production of gallic acid. Thus, for the present study, it has been taken up as a substrate for fermentation by tannase producing microorganism resulting in the biotransformation of myrobalan tannin to gallic acid. At present, India has to import to meet most of its gallic acid requirements. Myrobalan (Terminalia chebula) is abundantly available in India. If the utilization of myrobalan tannin as the substrate for submerged fermentation and the subsequent yield of gallic acid can be optimized, it will be of a great economic advantage in the Indian context. Myrobalan is a rich source of tannin and it contains $40 \%$ gallotannins of total tannins present. It is clinically used in folk medicine for a long time.

Hence in the present work we have suggested a method for the bioconversion of tannins derived from myrobalan into gallic acid, which has a wide application in various industries.

Gallic acid being an important precursor for trimethoxybenzaldehyde which in turn is a precursor for the production of trimethoprim, which is a broad spectrum antibiotic, is largely imported by pharmaceutical companies engaged in trimehoprim synthesis.

\section{Experimental}

\section{Materials}

Substrate: Myrobalan fruits (Terminalia chebula) they contain $40 \%$ tannins, out of which $35 \%$ are gallotannin.

\section{Microorganism}

Aspergillus niger (MTCC 282) obtained from Institute Microbial Technology, Chandigarh was used for the present work. Aspergillus niger grows on Czapek-yeast medium. It grows rapidly at room temperature $\left(25^{\circ} \mathrm{C}\right)$ and at $37^{\circ} \mathrm{C}$.

\section{Preparation of spore suspension}

$8 \mathrm{ml}$ of sterile distilled water was taken in $50 \mathrm{~mL}$ conical flask. The mycelia of the slant cultures were scraped off in $2 \mathrm{~mL}$ of distilled water. The resulting spore suspension was mixed to obtain a uniform suspension. This suspension was then added to distilled water to give $10 \mathrm{~mL}$ of spore suspension for spore dilution. $50 \mathrm{~mL}$ medium is transferred to each of $250 \mathrm{~mL}$ conical flask and then sterilized. These flasks were inoculated aseptically with 2 $\mathrm{mL}$ of spore suspension prepared from the culture slants. These flasks were kept in a rotatory shaker $(160 \mathrm{rpm})$ at $30 \pm 2^{\circ} \mathrm{C}$ for $48 \mathrm{~h}$. After $48 \mathrm{~h}$ of incubation the fungal mycelia was washed thoroughly with distilled water for subsequent studies this inoculum was used by centrifuging at $5000 \mathrm{rpm}$ for 15 minutes and wet mass is used as inoculum.

\section{Preparation of induced inoculum}

Tannase being an adaptive enzyme, pre induced inoculum is required to be prepared. The medium used for growing fungi, Aspergillus niger was potato dextrose broth containing $0.5 \%$ gallotannin adjusted to $\mathrm{pH}$ 5.6.

\section{Extraction of tannins}

Myrobalan fruits were obtained from Girijan Co-operative Corporation Ltd., Visakhapatnam. The fruits were dried and milled to get the particle size below $5 \mathrm{~mm}$. 
Tannins were extracted by autoclave at 10 PSI for half an hour. After 30 min the extract was filtered through cloth. This extract was evaporated and the obtained powder form was used for the entire experiment.

\section{Estimation of total tannins}

The following protein precipitation method was used for the quantitative determination of Tannins as described by Hagerman et al. ${ }^{5}$.

\section{Estimation of gallic acid produced by hydrolysis of gallotannin}

The fermented broth is taken in centrifugation tube and centrifuged for $5 \mathrm{~min}$. at 10,000 rpm. $0.025 \mathrm{~mL}$ of supernatant liquid is taken into $25 \mathrm{~mL}$, stoppered volumetric flask. 1.5 $\mathrm{mL}$ of $0.0667 \%$ methanolic Rhodanine solution was added to that after exactly $5 \mathrm{~min} .1$ $\mathrm{mL}$ of $0.5 \mathrm{~N}$ aqueous $\mathrm{KOH}$ was added. After 2-5 min. the mixture was diluted with distilled water. 5 - 10 min later the absorbance at $520 \mathrm{~nm}$ was read against reagent blank. The amount of gallic acid can be obtained from gallic acid standard curve.

\section{Estimation of gallotannin}

Extract was filtered through what man No.1 paper and the filtrate $(0.1 \mathrm{~mL})$ was diluted to $100 \mathrm{~mL}$ with $0.5 \mathrm{M}$ acetate buffer, $\mathrm{pH} 6.0$ and absorbance was recorded at $254 \mathrm{~nm}$ and 293 $\mathrm{nm}$, from the above absorbance the concentration of gallotannin was calculated by using formula

Concentration of gallotannin $(\mathrm{mg} / \mathrm{mL})=34.41\left(\mathrm{~A}_{293} \mathrm{X} 8\right)-6.98\left(\mathrm{~A}_{294} \mathrm{X} 6\right)$.

\section{Results and Discussion}

In the present work, studies on the gallic acid production from myrobalan using Aspergillus niger (MTCC 282) was carried out and the results were given in the Tables and Figs. The effect of various parameters at different ranges was studied and their influence on the fermentation was discussed in this paper.

\section{Effect of various factors on gallic acid production using strain Aspergillus niger (MTCC 282)}

\section{Effect of gallotannin concentration on gallic acid production}

The experiment was carried out to find out the effect of gallotannin concentration on gallic acid production. By keeping all the other parameters constant different concentrations of gallotannin ranging from $500 \mathrm{mg}$ to $3.5 \mathrm{~g}$ was used. As tannase is an inducible enzyme, it is induced by adding gallotannin as an inducer in the medium.

The optimum gallotannin concentration was found to be $1.5 \%(\mathrm{w} / \mathrm{v})$ by increasing gallotannin concentration from 0.5 to $1.5 \%(\mathrm{w} / \mathrm{v})$, the gallic acid production has also increased, and further increase has caused decrease in gallic acid production. The results were presented in the Table 1 and also shown in the Fig.1.

Optimal gallotannin concentration was reported as $2 \%(\mathrm{w} / \mathrm{v})$ by Bajpai et. $_{\text {al }}^{6}$. using immobilized fungal mycelia. Here in the present work free cells were used and optimal gallotannin concentration was found to be $1.5 \%(\mathrm{w} / \mathrm{v})$.

\section{Effect of nitrogen source on the production of gallic acid}

In order to evaluate the effect of Nitrogen source on gallic acid production, experiments were conducted by adding $0.001 \%(\mathrm{w} / \mathrm{v})$ organic and in organic nitrogen source separately to the fermentation medium. The results were presented in the Table 1 and also shown in the Fig .2. 
Table 1. Effect of some parameters on the hydrolysis of gallotannin to gallic acid by fungi A. niger

\begin{tabular}{|c|c|}
\hline Parameters & Gallic acid conc. $\mathrm{mg} / \mathrm{mL}$ \\
\hline \multicolumn{2}{|l|}{ 1. Gallo tannin conc. $\%(\mathrm{w} / \mathrm{v})$} \\
\hline 0.5 & 6.32 \\
\hline 1.0 & 6.24 \\
\hline 1.5 & 8.32 \\
\hline 2.0 & 8.08 \\
\hline 2.5 & 5.68 \\
\hline \multicolumn{2}{|l|}{ 2. Nitrogen source \& Metal ions } \\
\hline without N2 source & 8.35 \\
\hline Urea & $\begin{array}{l}8.35 \\
8.50\end{array}$ \\
\hline Amino acid & $\begin{array}{l}8.50 \\
8.28\end{array}$ \\
\hline without any metal & $\begin{array}{l}8.28 \\
8.36\end{array}$ \\
\hline $\mathrm{Cu}$ & 7.98 \\
\hline $\mathrm{Zn}$ & 8.68 \\
\hline $\mathrm{Fe}$ & $\begin{array}{l}0.00 \\
7.20\end{array}$ \\
\hline $\mathrm{Mg}$ & 7.78 \\
\hline EDTA & $\begin{array}{l}1.18 \\
7.02\end{array}$ \\
\hline \multicolumn{2}{|l|}{$\begin{array}{l}\text { 3. Concentration of urea \& Zinc } \\
(\% \mathrm{w} / \mathrm{v})\end{array}$} \\
\hline 0.001 & 8.12 \\
\hline 0.002 & 8.62 \\
\hline 0.003 & 8.68 \\
\hline 0.004 & 8.66 \\
\hline 0.001 & 8.18 \\
\hline 0.002 & 8.72 \\
\hline 0.003 & 8.70 \\
\hline 0.004 & 8.70 \\
\hline
\end{tabular}

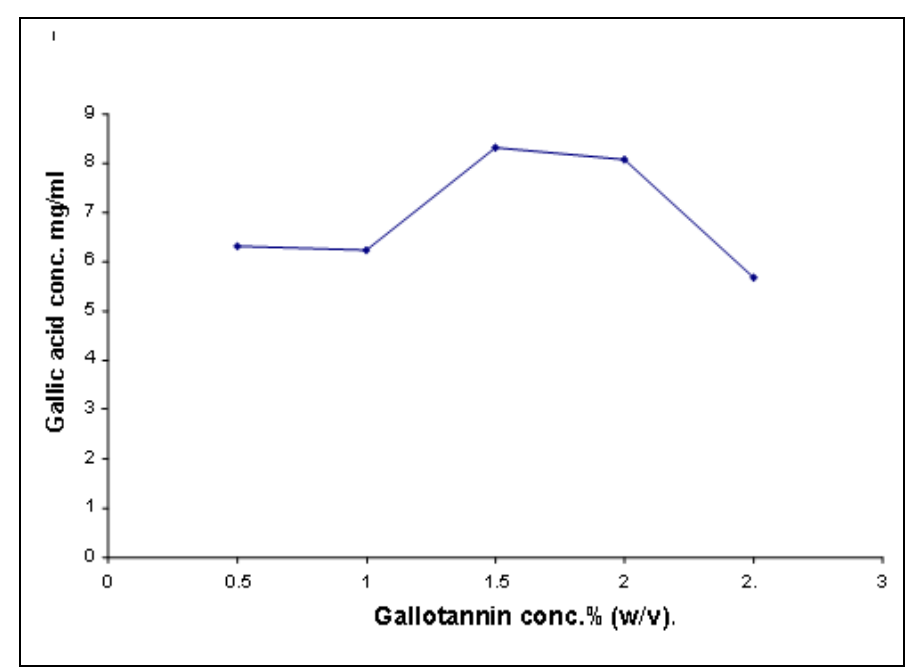

Figure 1. Effect of gallotannin concentration on gallic acid production. 
From the Fig. it can be observed that the inorganic nitrogen source i.e. urea increases gallic acid production where as organic nitrogen source i.e. amino acid tyrosine has no effect on gallic acid production. This may be due to the fact that the organism can readily assimilate inorganic nitrogen and utilize it for improving the enzymatic activity. No reports were available on the effect of $\mathrm{N}_{2}$ source on gallic acid production.

\section{Effect of metal ions and chelating agent on gallic acid production}

In order to evaluate the effect of metal ions and chelating agent on gallic and production, experiments were conducted by adding different metals to fermentation medium. Various metals like zinc, magnesium, copper and ferrous were added to the fermentation medium in a concentration of $0.001 \%(\mathrm{w} / \mathrm{v})$ chelating agent like EDTA was also added in $0.01 \%$ (w/v) concentration. The results were presented in the Table. 1 and also shown in Fig. 2.

From the Figure, it can be observed that gallic acid production is enhanced by adding $\mathrm{Zn}$ and decreased by other metals and chelating agent. This may be due to the fact that zinc acts as an activator for the enzyme whereas other metals and chelating agents inactivate the enzyme.

\section{Effect of urea on the production of gallic acid}

In order to evaluate the effect of urea on Gallic acid production, experiments were conducted by varying concentrations of urea ranging from $0.001 \%$ (w/v) to $0.004 \%$ $(w / v)$. The results were presented in the Table 1 . and shown in the Fig. 3. From the Figure, it can be observed that the optimum urea concentration is $0.003 \%$ (W/V). Further increase in connection does not cause and increase in the Gallic acid production. This may be due to availability of enough nutrient.

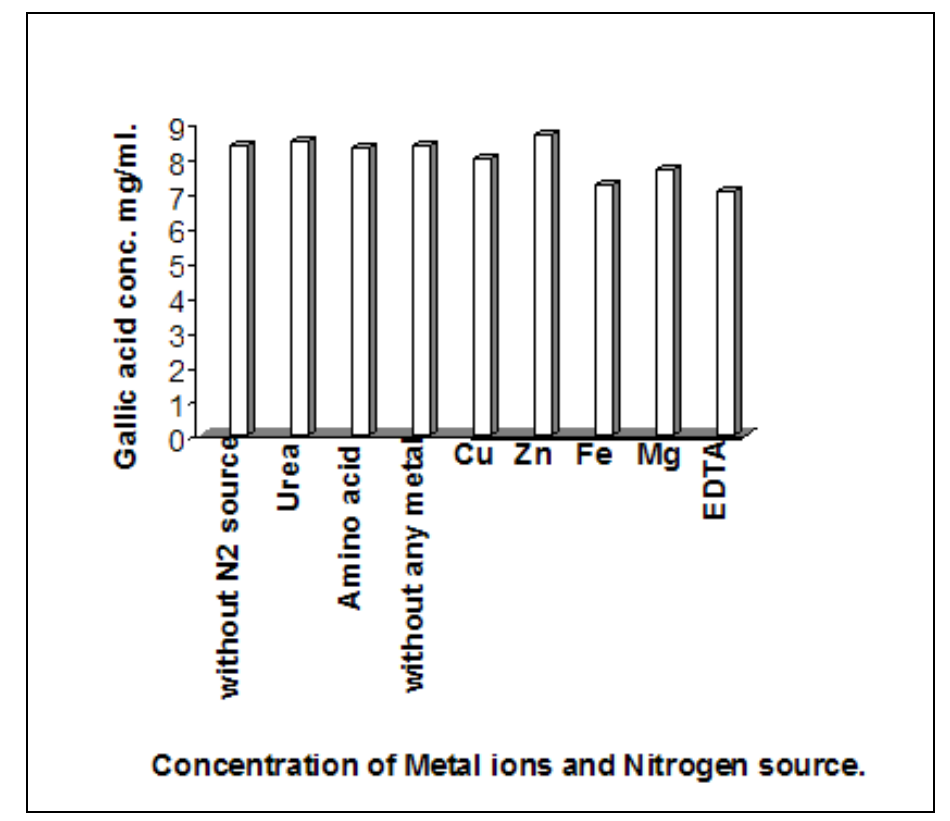

Figure 2. Effect of nitrogen source, metal ions and chelating agent on gallic acid production. 


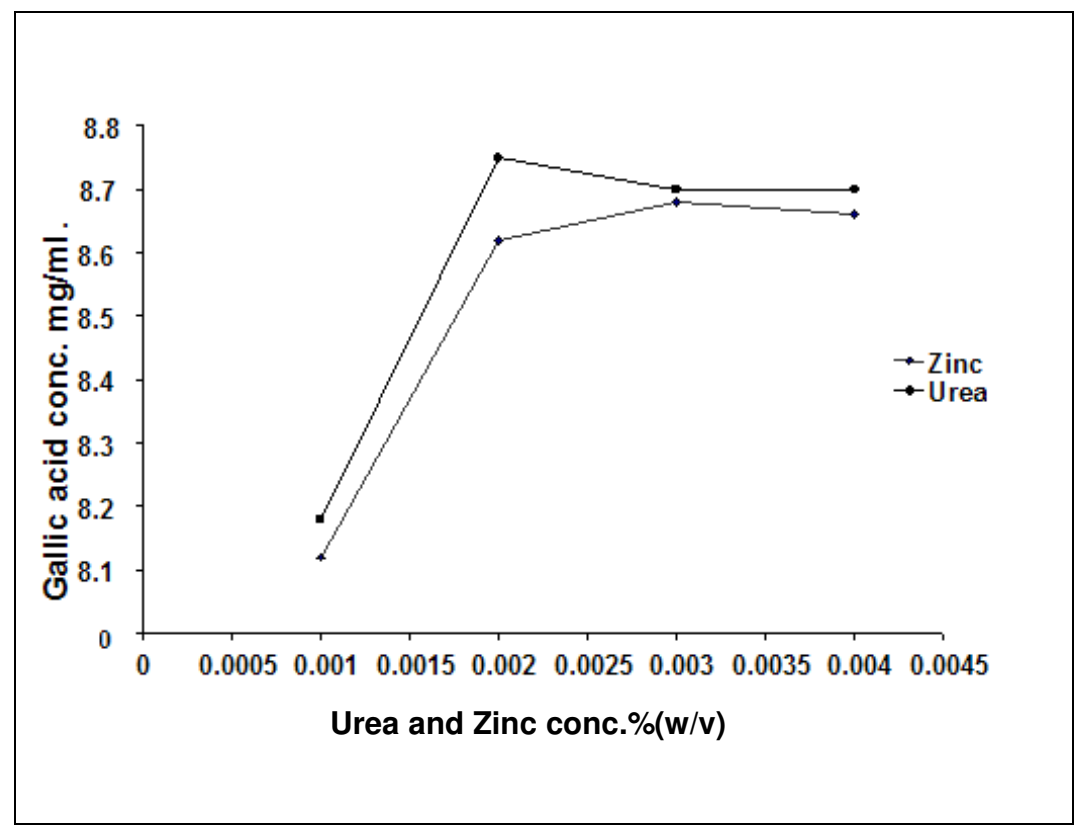

Figure 3. Effect of urea and zinc conc. on gallic acid production.

\section{Effect on zinc on the production of gallic acid}

In order to evaluate the effect of zinc on gallic acid production, experiments were conducted by varying concentrations of zinc ranging from $0.001 \%(\mathrm{w} / \mathrm{v})$ to $0.004 \%(\mathrm{w} / \mathrm{v})$. The results were presented in the Table 1 and shown in the Fig. $3 . \quad$ From the Figure it can be observed that the optimum zinc concentration was observed to be $0.002 \%(\mathrm{w} / \mathrm{v})$. The production of gallic acid increased with increase in zinc concentration up to $0.002 \%$ $(\mathrm{w} / \mathrm{v})$. Further increase in $\mathrm{Zn}$ concentration did not increase the gallic acid production further. This may be due to saturation of the activator.

\section{Production of gallic acid at optimal conditions}

This experiment was carried out using all the optimized values i.e. gallotannin conc. $1.5 \%$ (w/v), urea conc. $0.003 \%(\mathrm{w} / \mathrm{v})$, zinc conc. $0.002 \%(\mathrm{w} / \mathrm{v})$ and fermentation time $90 \mathrm{~min}$. The maximum yield of $7.42 \mathrm{mg} / \mathrm{mL}$ gallic acid was observed. The results obtained were presented in Table 2 and shown in the Figure 4.

Table. 2. Production of gallic acid at optimal conditions:

\begin{tabular}{ccc}
\hline S.No. & Time (min.) & $\begin{array}{c}\text { Gallic acid conc. In } \\
(\mathrm{mg} / \mathrm{mL})\end{array}$ \\
\hline 1. & 30 & 5.92 \\
2. & 60 & 7.34 \\
3. & 90 & 7.62 \\
4. & 120 & 6.70 \\
5. & 150 & 6.66 \\
\hline
\end{tabular}




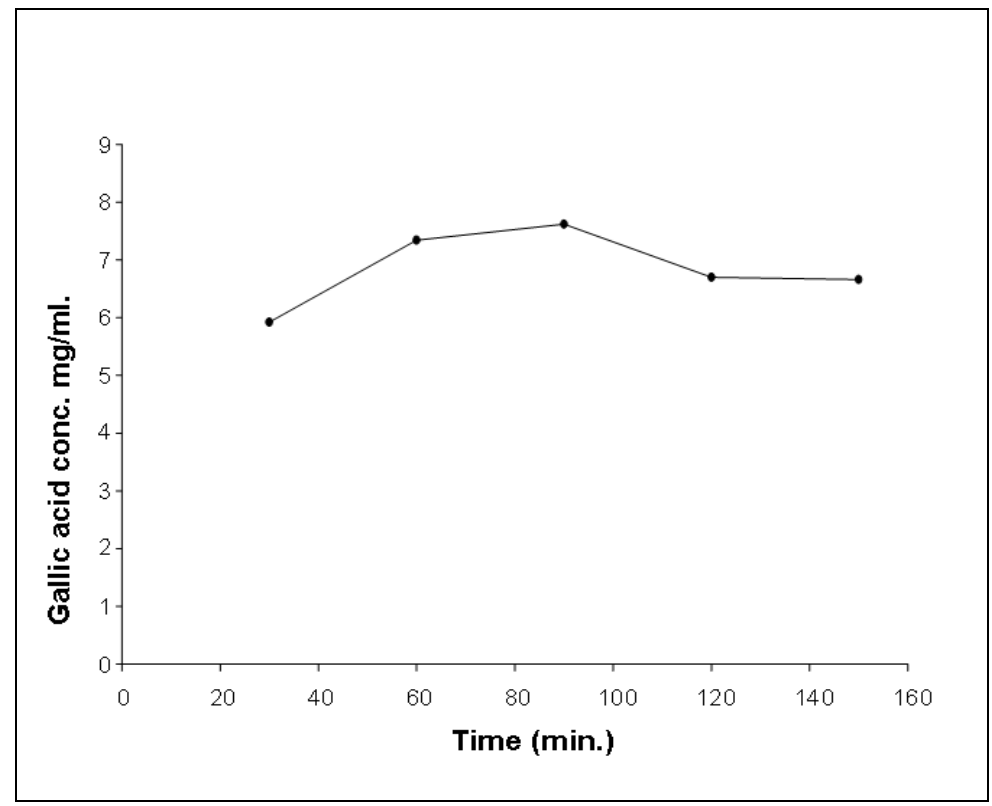

Figure 4. Gallic acid production at optimal conditions.

\section{Conclusions}

There was no report till date on metal ions on gallic acid production. Hence, in the present work has been taken up with a view of exploring the possibilities of using myrobalan as a substrate for the production of gallic acid by using fungal mycelia. The concentration of produced gallic acid at all optimized parameters is $7.68 \mathrm{mg} / \mathrm{ml}$ which corresponds to $74 \%$ yield. The total extractable tannin concentration of the substrate was $40 \%(\mathrm{w} / \mathrm{v})$. Gallotannin concentration was estimated to be $38 \%$ (w/v) of total tannins. By using present technique gallic acid yield was about $72 \%$. Thus this gallic acid production from wild forest tannin rich material i.e. myrobalan would help the country to produce gallic acid from cheap resources not only to meet indigenous demand but also to export gallic acid to other developing nations.

\section{References}

1. Kudson K, J. Biol. Chem, 1913, 14,159-202.

2. Pourrat H, Regrat F and Pourrat A, Biotechnol. Left, 1982, 4,583 - 588.

3. Lekha P K and Lonsane B K, State of the art. Adv. Appl. Microbiol, 1997, 44, 215.

4. Mukharjee G and Banerjee R Chim Oggi Chem Today, 2003, 21(1/2), 59-62.

5. Haggerman A E and Butler L G, J. Agric. Food. Chem, 1978, 26, $809-812$.

6. Bajpai and Patil Ind. J. Experimental Biology, 37, 94-97. World J. Microbiol. Biotechnol. 15, 673-677. 


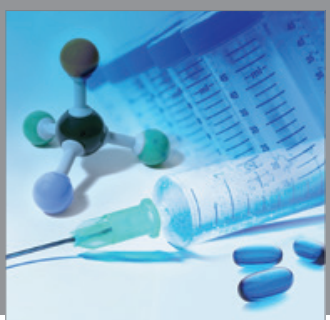

International Journal of

Medicinal Chemistry

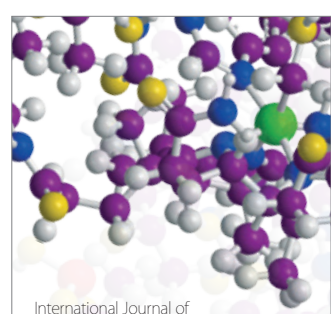

Carbohydrate Chemistry

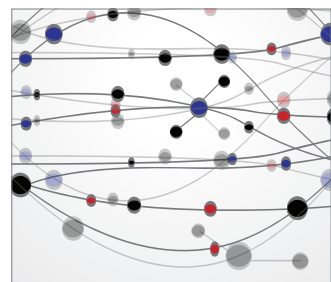

The Scientific World Journal
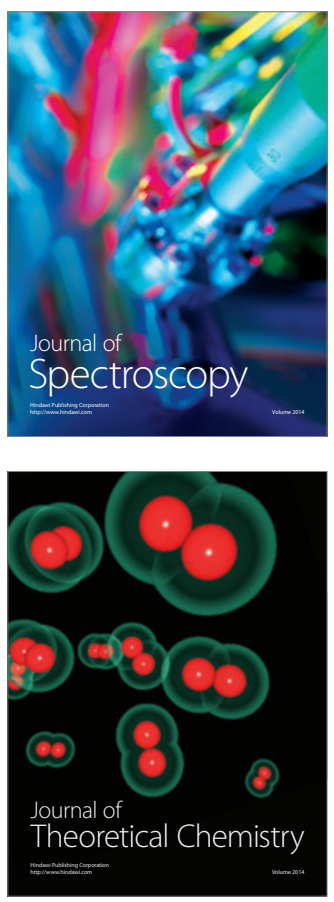
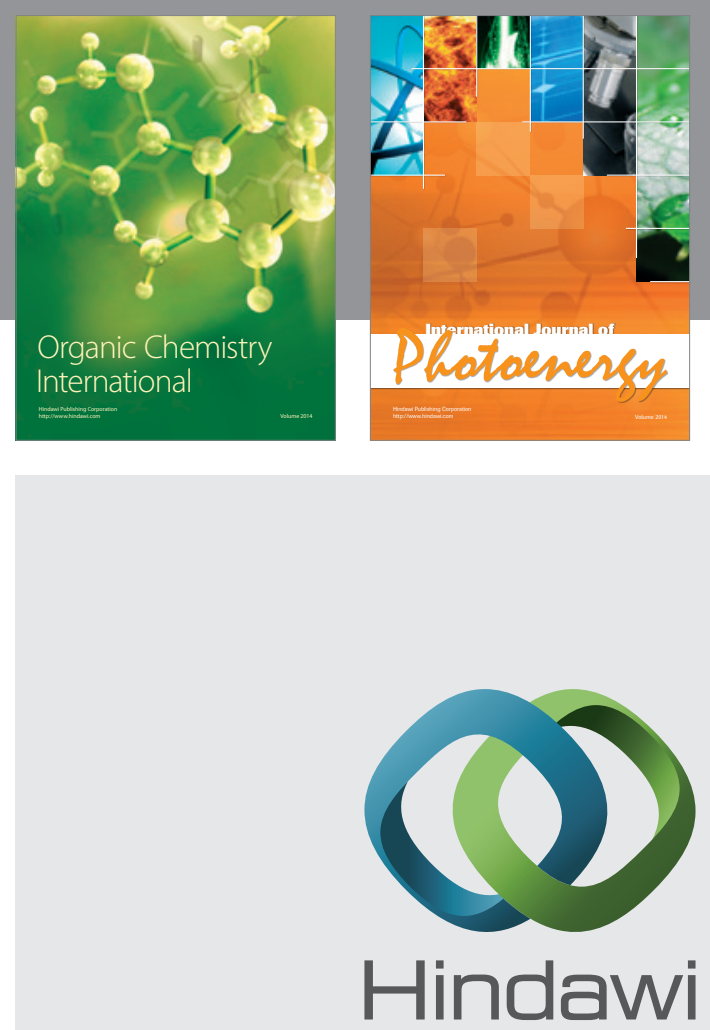

Submit your manuscripts at

http://www.hindawi.com
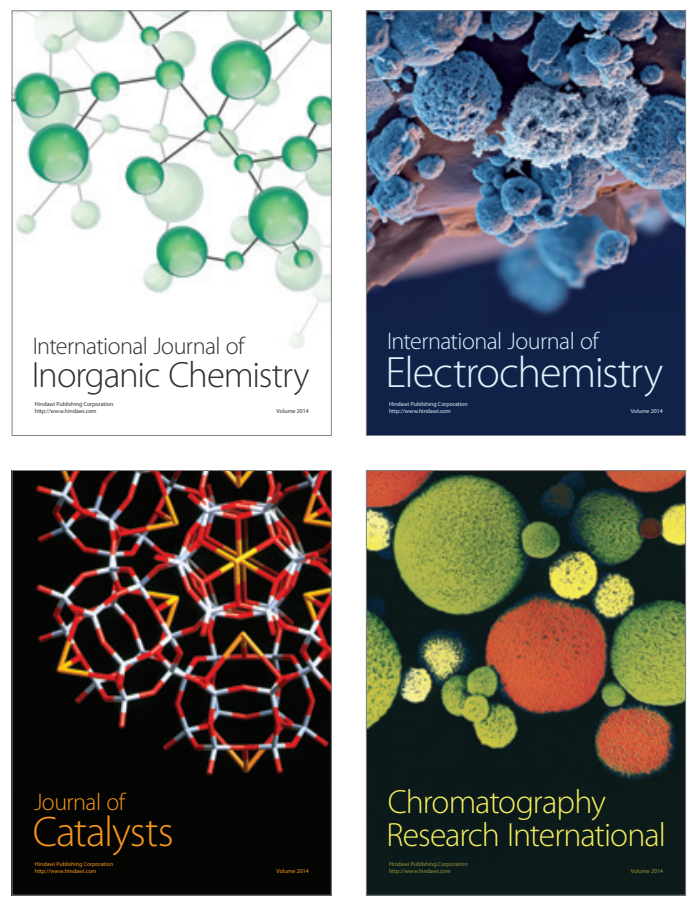
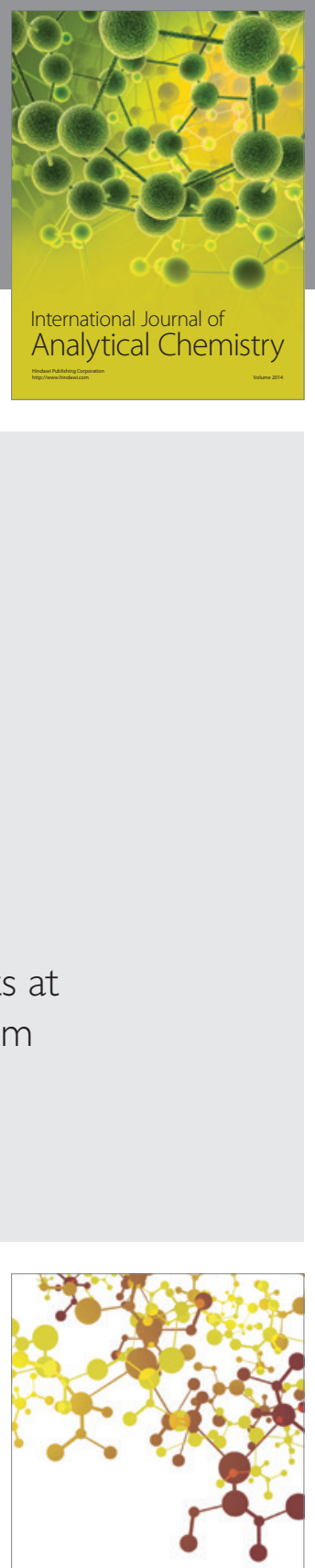

Journal of

Applied Chemistry
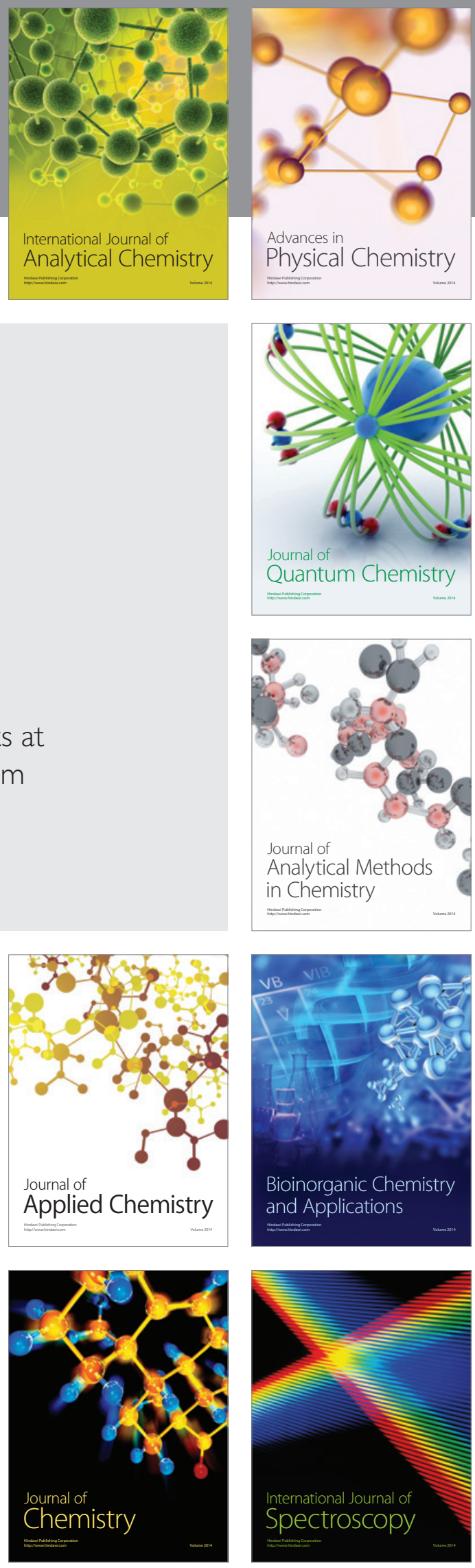